\title{
IMMUNOLOGICAL CHARACTERISATION OF RUBELLA VIRION POLYPEPTIDES
}

\author{
Linda Ho-Terry, A. Cohen and R. S. Tedder* \\ Department of Medical Microbiology, Faculty of Clinical Sciences, University College, \\ London WCIE 6JJ and ${ }^{*}$ Department of Virology, Middlesex Hospital Medical School, \\ Riding House Street, London WIP 7 PP
}

\begin{abstract}
Summary. Antibodies specific for rubella virion polypeptide, VPI, secreted by clones of hybridoma cells or produced in rabbits in response to specific antigenic stimulation, located determinants for haemagglutination inhibiting ( $\mathrm{HI})$ and neutralising $(\mathrm{Nt})$ antibodies on this envelope component.
\end{abstract}

\section{INTRODUCTION}

Recently, we adduced some evidence that the antigenic determinants on rubella virus for production of haemagglutination-inhibiting ( $\mathrm{HI})$ and virus neutralising $(\mathrm{Nt})$ antibodies are associated with different envelope polypeptides (Ho-Terry and Cohen, 1980). The availability of rubella antibodies specific for individual envelope components made a more detailed correlation between antigenic properties, biological function and structural virion components possible.

\section{MATERIALS AND METHODS} 1979).

Cells, virus, culture media and buffers were as previously described (Ho-Terry and Cohen,

Radioactive $L-\left(5-{ }^{3} \mathrm{H}\right)$ arginine monohydrochloride $(8 \cdot 8 \mathrm{Ci} / \mathrm{mmol})$ was obtained from the Radiochemical Centre, Amersham, Bucks.

Mouse ascitic fluid containing hybridoma antibodies to rubella HA was produced as described by Tedder, Yao and Anderson (1982). The ascitic fluid was absorbed before use with BHK-21 cell extracts to remove antibodies that cross-reacted with BHK cells. Dilutions of absorbed whole ascitic fluid were used in subsequent experiments.

Rabbit antibodies. Rubella envelope polypeptides VPI and VPII were prepared as previously described (Ho-Terry and Cohen, 1980). Three VPI-containing gel slices or three VPII-containing gel slices, initially ground with a glass rod, were further homogenised by repeated forcing through a needle with a bore diameter of $0.63 \mathrm{~mm}$. The homogenate was mixed with $0.6 \mathrm{ml}$ of complete Freund's adjuvant by repeatedly drawing into and expelling from a syringe and then injected subcutaneously into a rabbit. Four weeks after the initial injection, the rabbit received three further injections of similar material at weekly intervals.

Enzyme-linked immunosorbent assay (ELISA). Rubella virion polypeptides were separated by electrophoresis in polyacrylamide gels and eluted from individual gel fragments into separate wells of ELISA grade polystyrene microplates to serve as the solid-phase antigen. These 
polypeptides were then tested against appropriate antibodies by the indirect ELISA procedure described by Vaheri and Salonen (1980).

Haemagglutination ( $H A)$ and haemagglutination inhibition $(H I)$ tests were performed as described by Liebhaber (1970 $a$ and $b$ ). 1980).

Neutralisation $(\mathrm{Nt})$ tests were performed as previously described (Ho-Terry and Cohen,

\section{RESULTS}

\section{Virion polypeptides}

Purified rubella virus labelled with ${ }^{3} \mathrm{H}$-arginine was immunoprecipitated with human rubella convalescent serum and analysed by electrophoresis in polyacrylamide gel. The electropherogram illustrated in fig. 1 shows the three virion polypeptides of rubella virus; two of them, the 55K (VPI) and 47-45K (VPII) polypeptides, have been identified as components of the virus envelope (Ho-Terry and Cohen, 1980).

\section{Immunological characterisation}

After separation by electrophoresis in polyacrylamide gel the envelope polypeptides were eluted from individual gel fragments into individual microplate wells. The bound envelope polypeptides were then to treated with ascitic fluid containing

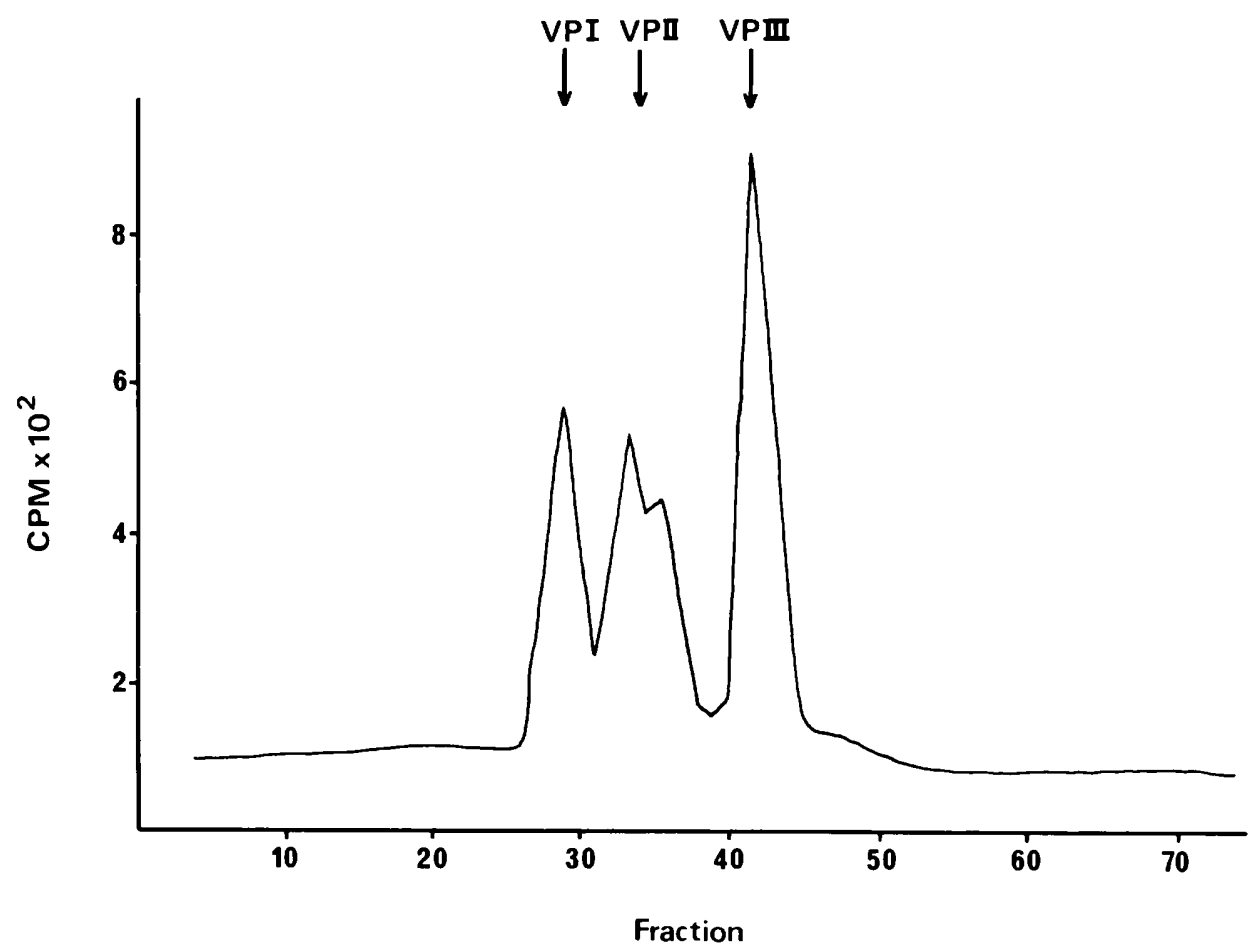

FIG. 1.-Polyacrylamide gel electrophoresis of purified ${ }^{3} \mathrm{H}$-arginine labelled immunoprecipitated rubella virus. 


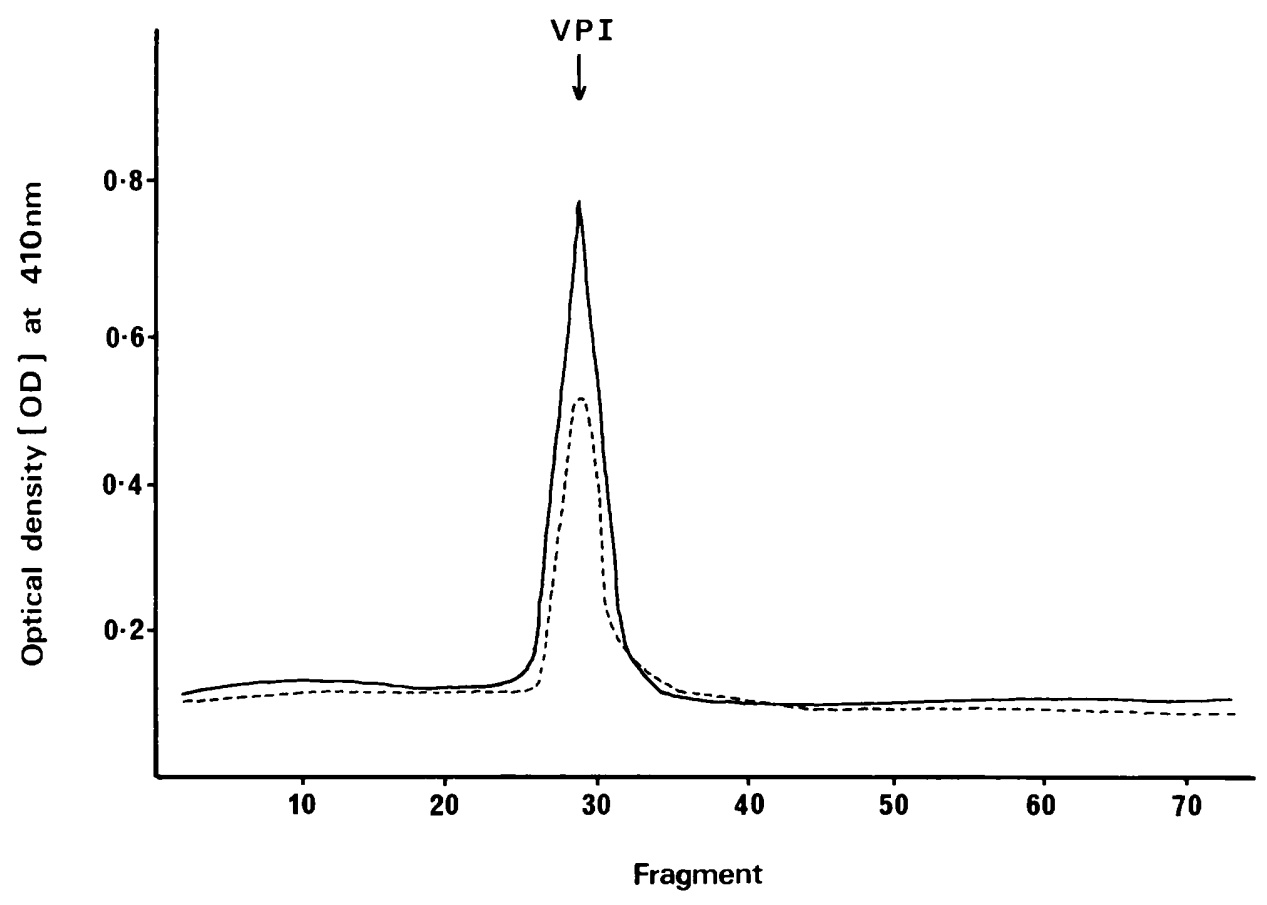

FIG. 2.-Polypeptide specificity of hybridoma antibodies. Each gel fragment used as a solid-phase antigen was treated with hybridoma antibodies and absorbance values were obtained with alkaline-phosphatase-labelled anti-human IgG. $-=\mathrm{E} 1 \mathrm{~F} 3 ; \ldots=\mathrm{C} 10 \mathrm{~F} 7$.

rubella-specific antibodies from clones of hybridoma cells in the indirect ELISA test. Of the four cloned hybridoma antibodies tested, two reacted solely with VPI (fig. 2). Previously, we demonstrated indirectly that HI antibodies react with VPI. Experiments summarised in the table show that both antibodies monospecific for VPI inhibited HA but one of them also neutralised infectivity. VPI, therefore, carries antigenic determinants for both $\mathrm{HI}$ and $\mathrm{Nt}$ antibodies.

To characterise VPI and VPII further, antibodies to each of these components, isolated and purified by gel electrophoresis (Ho-Terry and Cohen 1980), were raised in rabbits. Treatment of the individual virion components with sodium dodecyl sulphate (SDS) and 2-mercaptoethanol (2ME), which is essential for their isolation, markedly reduced their immunoreactivity (unpublished observations). The antisera obtained reacted only at low titre, but whereas that raised against VPI was monospecific, that

TABLE

Immunoreactivity of antibodies against rubella virion polypeptides

\begin{tabular}{|c|c|c|}
\hline \multirow[b]{2}{*}{ Antiserum } & \multicolumn{2}{|c|}{ Antibody titre in } \\
\hline & HI test & Nt test \\
\hline $\begin{array}{l}\text { Mouse anti-VPI (E1F3) } \\
\text { Mouse anti-VPI (C10F7) } \\
\text { Rabbit anti-VPI } \\
\text { Rabbit anti-VPII }\end{array}$ & $\begin{array}{l}1.6 \times 10^{6} \\
3 \cdot 2 \times 10^{4} \\
<4 \\
<4\end{array}$ & $\begin{array}{l}8 \times 10^{4} \\
<10^{2} \\
10 \\
20\end{array}$ \\
\hline
\end{tabular}




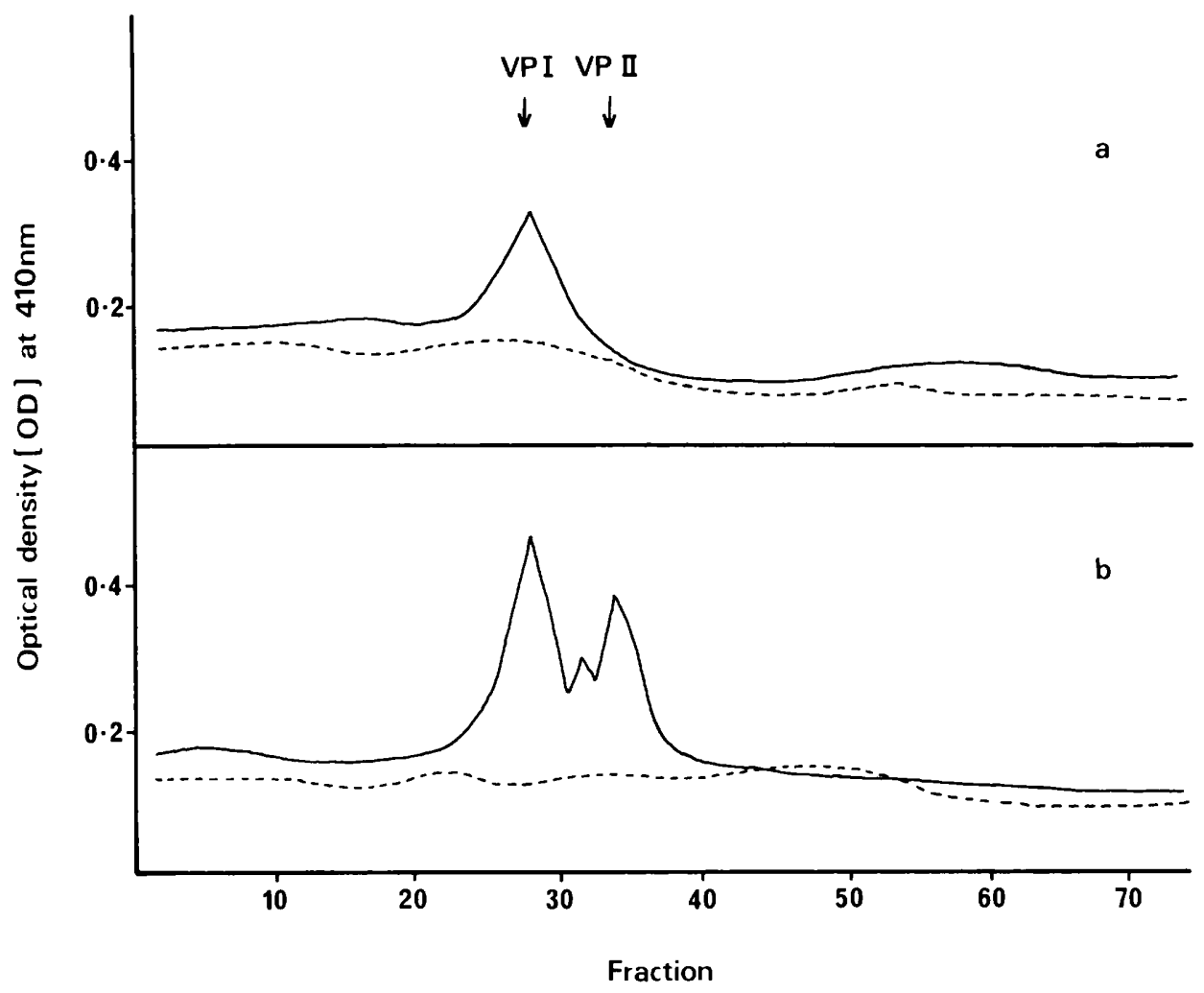

FIG. 3.-Polypeptide specificity of rabbit antibodies raised against (a) VPI and (b) VPII. - - - = preimmune

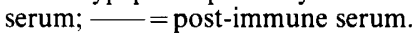

raised against VPII cross-reacted with VPI (fig. 3). Both sera had neutralising activity (table) but the presence of $\mathrm{Nt}$ antibodies in the monospecific antiserum confirms that some $\mathrm{Nt}$ antigenic determinants are located on VPI. The absence of $\mathrm{HI}$ activity from the rabbit antisera is probably of quantitative rather than qualitative significance.

\section{DisCUSSION}

The results obtained with hybridoma antibodies monospecific for VPI located HI and Nt determinants on VPI. However, because HI and Nt activities of antibodies monospecific for VPI do not always correlate (table) the antigenic determinants responsible are apparently distinct. Moreover, both hybridoma antibodies tested inhibited HA although recognising different epitopes in cross-blocking experiments (Tedder et al., 1982), which indicates that there must be at least two distinct HI sites on VPI. The rabbit antibodies reacting with VPII were heterospecific, indicating some homology in the antigenic structure of the two envelope components. Possibly, this homology may be revealed only after denaturation by the SDS and 2ME treatment required for isolation of the individual envelope components. The expression of different antigenic determinants by native and denatured protein has been demonstrated by Ruoslahti and Engvall (1976). In spite of the immunological cross- 
reactivity, each envelope component is unique by peptide mapping (Ho-Terry and Cohen, 1982).

We would like to thank P. Londesborough for technical assistance, Dr G. P. Gladstone for helping with preparation of rabbit antisera and the Peel Medical Research Trust for financial support.

\section{REFERENCES}

Ho-Terry L, Cohen A 1979 Radioimmunoassay for antibodies to rubella virus and its ribonucleoprotein component. Journal of Medical Microbiology 12:44I-448.

Ho-Terry L, Cohen A 1980 Degradation of rubella virus envelope components. Archives of Virology 65:1-13

Ho-Terry L, Cohen A 1982 Rubella virion polypeptides: characterization by polyacrylamide gel electrophoresis, isoelectric focusing and peptide mapping. Archives of Virology 72:47-54.

Liebhaber H 1970a Measurement of rubella antibody by hemagglutination inhibition. I. Variables affecting rubella hemagglutination. Journal of Immunology 104:818-825.

Liebhaber H 1970b Measurement of rubella antibody by hemagglutination inhibition. II. Characteristics of an improved HAI test employing a new method for the removal of non-immunoglobulin HA inhibitors from serum. Journal of Immunology 104:826-834.

Ruoslahti E, Engvall EE 1976 Immunological crossreaction between alpha-fetoprotein and albumin. Proceedings of the National Academy of Sciences, USA 73:4641-4644.

Tedder R S, Yao J L, Anderson M J 1982 The production of monoclonal antibodies to rubella haemagglutinin and their use in antibody-capture assays for rubella-specific IgM. Journal of Hygiene 88:335-350.

Vaheri A, Salonen E-M 1980 Evaluation of solid phase enzyme-immunoassay procedure in immunity surveys and diagnosis of rubella. Journal of Medical Virology, 5:171-181. 